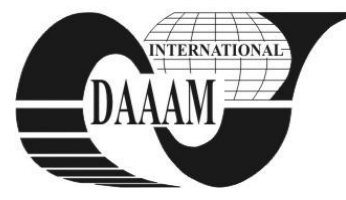

Annals of DAAAM for 2011 \& Proceedings of the 22nd International DAAAM Symposium, Volume 22, No. 1, ISSN 1726-9679 ISBN 978-3-901509-83-4, Editor B. Katalinic, Published by DAAAM International, Vienna, Austria, EU, 2011 Make Harmony between Technology and Nature, and Your Mind will Fly Free as a Bird Annals \& Proceedings of DAAAM International 2011

\title{
SOUND ABSORPTION OF MULTILAYERED SAMPLES COMPOSED BY DIFFERENT POROUS MATERIALS AND PERFORATED FACING
}

\author{
LUMEI, C[alin] V[asile]; ARGHIR, M[ariana] \& GARAI, M[assimo]
}

\begin{abstract}
This paper reports the results of normal incidence sound absorption measurements done over three different acoustic materials with varying thickness. A microperforated panel (MPP) was added to cover the absorber, in some cases leaving an air cavity between them. The measurements were done in an impedance tube, according to ISO 10534-2:1998. The aim was to find the best setup of the test samples to build a device that improves the absorption especially at low frequency. It is concluded that having the acoustic materials in contact with the MPP and backed by an air layer gives the expected results.
\end{abstract}

Key words: measurement, microperforated, absorption, porous material

\section{INTRODUCTION}

The growing need for quieter environment has caused people to take into consideration the use of noise barriers as a measure to reduce the noise level. Noise barriers can be briefly defined as being reflective, absorptive or reactive (Kotzen, 2009). By their nature, reflective barriers are not as effective as those absorbtive or reactive, especially when there is one of them on each side of the roadway. Building absorptive noise barriers usually involves a porous element that absorbs noise.

Porous materials used can be e.g. concreted woodfiber which can form the surface of the barrier, or less rigid materials, as mineral wool or polyester fiber. The latter ones, owing to their sensibility against weather conditions, need a protection layer. Usualy those facings are microperforated, to improve the sound absorption due to resonant effect.

\section{THEORY AND DESIGN OF TEST SAMPLES}

The device taken into consideration is composed of a rigid backed fibrous material and a microperforated panel. Figure 1 shows the placement of test samples.

The concept of microperforation was first developed in the late sixties by Maa (Maa 1975). Usualy we refer to a microperforated panel when we have submilimeter size diameter holes and sheet thickness. For a MPP with very small openings, damping is achieved by the viscous losses within the neck.

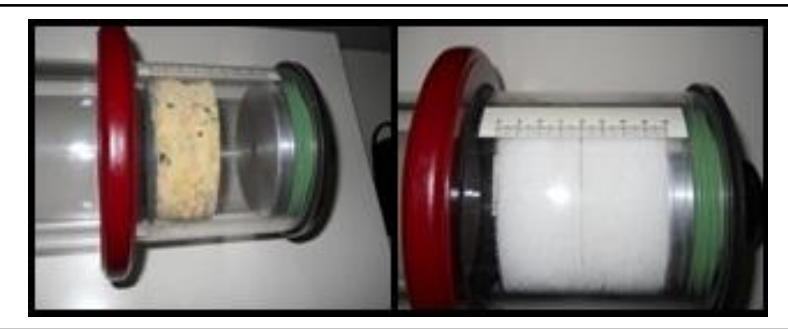

Fig. 1. Setup of thest samples for measurement: a - MPP + absorber + air, b - MPP + absorber



Fig. 2. Test samples: a - polyester fiber (type 1), b - polyester fiber (type 2), c - polyurethane, d-MPP

When the space between the MPP and the wall is empty there is a very sharp absorption bandwidth. To increase the acoustic resistance of the device, thus the absorption, the space between the rigid backing and MPP is filled with fibrous or porous boards; usually they are placed where the particle velocity is maximum (Cox \& D'Antonio 2009).

The advantage of using a microperforated panel to cover a porous material, besides being a protective sheet, lies in increasing the sound absorption by the "Helmholtz resonance effect". Low frequency absorption increases with the increase of holes diameter, at the expense of a loss at higher frequencies (Ingard \& Bolt 1951).

Microperforated panel can be produced from any sheet material: metal, plastic, cardboard or plywood.

For each porous material type, there are characteristics that can influence the design and performance of a barrier, like porosity, density, fiber diameter and density.

The test samples used for measurements were three different porous materials and a microperforated panel. The first type of porous material was polyester fiber made from recycled bottles (fig. $2 \mathrm{a}$ and $2 \mathrm{~b}$ ) with two distinct densities. The second sample was made of polyurethane with small inclusions (fig. 2c). The MPP was a sheet made of steel, with thickness and holes diameter of $1 \mathrm{~mm}$ (fig. 2d). The properties of the test samples are described in Table 1.

The polyester fiber samples were cut in two different thicknesses, $50 \mathrm{~mm}$ and $80 \mathrm{~mm}$; the polyurethane specimen had thicknesses of 40 and $80 \mathrm{~mm}$.

\begin{tabular}{|l|c|c|c|c|}
\hline \multicolumn{1}{|c|}{ Sample } & Porosity & $\begin{array}{c}\text { Fiber } \\
{[\%]}\end{array}$ & $\begin{array}{c}\text { Density } \\
\text { diameter }\end{array}$ & $\begin{array}{c}\text { Airflow } \\
\text { resistivity } \\
{[\mathrm{Pa} / \mathrm{m}]}\end{array}$ \\
\hline Polyester Fiber (PF-1) & 98 & 30 & 40 & 3700 \\
\hline Polyester Fiber (PF-2) & 98 & 30 & 25 & 2000 \\
\hline Polyurethane (PU) & 98 & - & 60 & 8000 \\
\hline MPP & 23 & - & - & - \\
\hline
\end{tabular}

Tab. 1. Test sample properties

\section{THE MEASUREMENT METHOD}

The measurements were made in an impedance tube (fig. 3) using the transfer function method (ISO 10534-2), from where 
the specific acoustic impedance ratio and absorption coefficient was calculated.

The normal incidence absorption coefficient was obtained on the frequency range $100-1900 \mathrm{~Hz}$.

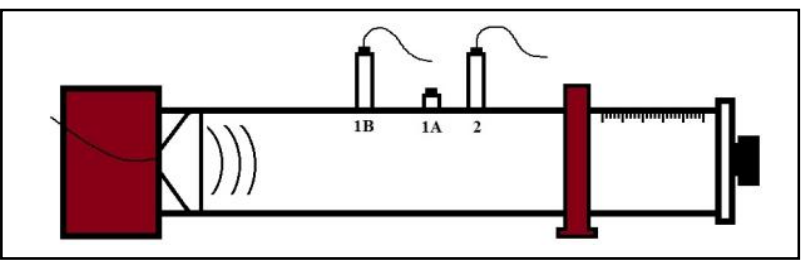

Fig. 3. Schematic view of the impedance tube used for measurements

\section{MEASUREMENTS AND RESULTS}

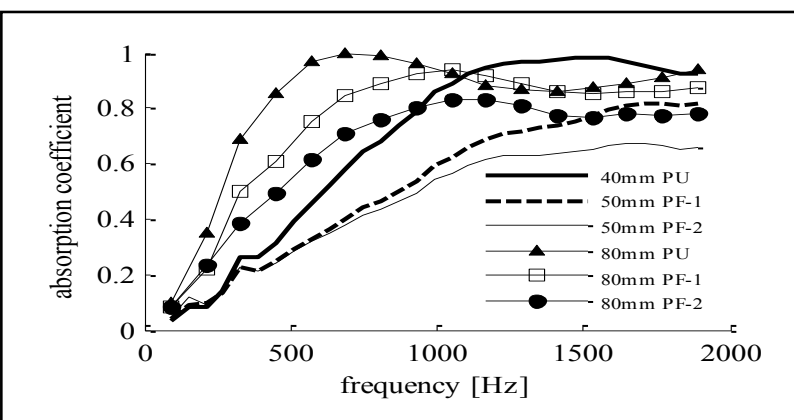

Fig. 4. Absorption coefficient for the device composed of a MPP + acoustic material

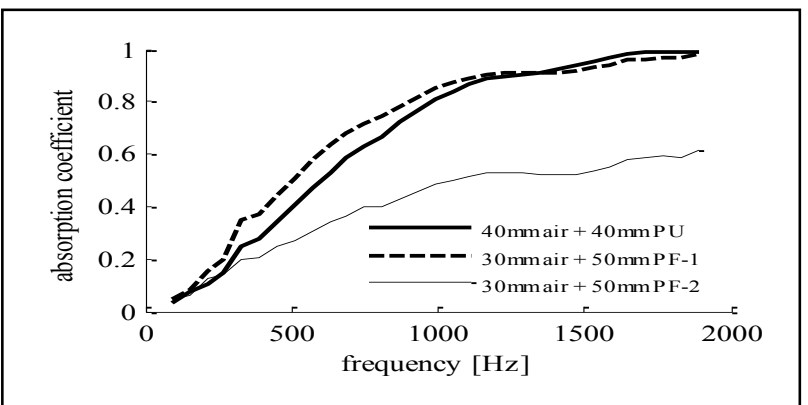

Fig. 5. Absorption coefficient for the device composed of a MPP + air layer + acoustic material

For the first set of measurements, the space between the rigid backing and the MPP was filled with the acoustic material having thickness of $40 \mathrm{~mm}$ (PU), $50 \mathrm{~mm}$ (PF-1, PF-2) and 80 $\mathrm{mm}$ (PF-1, PF-2, PU). Sound absorption was measured for each sample (Fig. 4), to see the effect of material thickness on absorption coefficient.

As expected, the absorption increases as thickness of material increases. In figure 4 we can also see that the samples with a higher density and flow resitivity, gives a better absorption. The best absorption was given by the sample made of polyurethane. It is important to mention that this setup acted somehow like a resonating absorber, having the highest absorption peak around $700 \mathrm{~Hz}$, thus improving the efficiency at lower frequencies.

For the second set of measurements the thickness of the device was $80 \mathrm{~mm}$. An air layer was left between the MPP and samples of 40 and $50 \mathrm{~mm}$. Results are plotted in Figure 5.

Samples were kept the same for the third set of measurements (fig. 6), but the air layer was placed behind the porous material.

Adding an air cavity between the porous absorber and the perforated facing decreases the absorption (fig. 5). In the other case, when the air layer is placed behind the absorber (fig. 6), the performance of the device increases.
In figure 7 , it has been presented a comparision between two sets of measurements, for the $80 \mathrm{~mm}$ device, one with the cavity filled with the absorber, and the other one having the absorber backed by an air layer. The difference in sound absorption is minimum for the polyurethane and polyester fiber (type 1) samples.



Fig. 6. Absorption coefficient for the device composed of a MPP + acoustic material + air layer



Fig. 7. Comparision of different absorption coefficients

\section{CONCLUDING REMARKS}

From the results and discussions presented above it can be seen that a perforated sound absorbing system is a very adaptable type of noise reducing device. Density, thickness and the placement of the absorbing material have a major influence on increasing the sound absorption.

It can also be concluded that low frequency absorption can be achieved by spacing the acoustic material out from the wall, the resulting setup being as efficient as the one with the same thickness filled with absorber.

\section{ACKNOWLEDGEMENTS}

Financial support by the European Social Fund (project SIDOC/88/1.5/S/60078) is gratefully acknowledged. Measurements were performed at the Applied Acoustics laboratory at the University of Bologna.

\section{REFERENCES}

Cox, T. J.; D'Antonio, P. (2009). Acoustic absorbers and diffusers: theory, design and application, Taylor \& Francis, ISBN 9780415471749, New York

Ingard, U.; Bolt, H. (1951). Absorption Characteristics of Acoustic Material with Perforated Facings. The Journal of the Acoustical Society of America, Vol. 23, No. 5, (September 1951), 533-540, ISSN 00014966

Kotzen, B.; English, C. (2009). Environmental noise barriers: a guide to their acoustic and visual design, Taylor \& Francis, ISBN 9780415437080, New York

Maa, D-Y. (1975). Theory and design of microperforated panel sound-absorbing constructions. Scientia Sinica, Vol. 18, No. 1, (1975), 55-71

***ISO 10534-2:1998, "Acoustics - determination of sound absorption coefficient and impedance in impedance tubes" 